\title{
PKM UJI KOMPETENSI BIDANG KEAHLIAN AKUNTANSI DI SMK NEGERI 1 PEMATANGSIANTAR
}

\author{
Elidawaty Purba'), Taufik Parinduri'2), Vitryani Tarigan ${ }^{3)}$, Wico Jontarudi Tarigan ${ }^{4)}$, \\ Djuli Sjafei Purba ${ }^{5}$
}

\author{
${ }^{1)}$ Fakultas Ekonomi, Universitas Simalungun, Pematangsiantar, Sumatera Utara, Indonesia \\ Corresponding author : Wico Jontarudi Tarigan \\ E-mail : ico180285@gmail.com
}

Diterima 06 November 2021, Disetujui 09 November 2021

\begin{abstract}
ABSTRAK
SMK Negeri 1 Pematangsiantar meminta kepada Universitas Simalungun dalam hal ini adalah Fakultas Ekonomi untuk melaksanakan uji kompetensi kepada siswa-siswi yang duduk di kelas XII. Uji Kompetensi sebagai salah satu syarat kelulusan bagi siswa/siswi. Uji Kompetensi Keahliaan bagi siswa siswi bertujuan a) mengukur pencapaian kompetensi siswa SMK b) memfasilitasi siswa/siswi mendapatkan sertifikat uji kompetensi c) mengoptimalkan pelaksanaan sertifikasi kompetensi siswa/siswi SMK sesuai Kerangka Nasional Indonesia d) memfasilitasi SMK bekerjasama dengan dunia usaha/industri sesuai kebutuhan dunia usaha dan dunia industri. Uji Kompetensi Keahlian dilaksanakan selama 4 hari yaitu tanggal 5 April 2021 sampai dengan 8 April 2021. Uji kompetensi ini tidak hanya oleh dunia Universitas tetapi juga melibatkan dunia usaha yaitu pada saat pelaksaan ujian wawancara. Berdasarkan hasil yang diperoleh pada saat pelaksanaan, Tim Pengabdi dari Fakultas Ekonomi Universitas Simalungun, Tim dari dunia usaha dan Tim dari SMK Negeri 1 Pematangsiantar menyatakan semua peserta dinyatakan lulus. Evaluasi atas proses pelaksanaan kegiatan dilakukan dengan memberikan angket kepada siswa/siswi peserta uji kompetensi. Dan hasil yang didapat $25 \%$ memberikan jawaban sangat baik, 60\% memberikan jawaban baik dan 15\% memberikan jawaban cukup. Sehingga ke depan pelaksanaan ujian kompetensi dilakukan perbaikan sebagaimana saran dari siswa agar ketika ujian praktek akuntansi sudah masing - masing siswa menggunakan Komputer
\end{abstract}

Kata kunci: uji kompetensi; SMK; Siswa; akuntansi

\begin{abstract}
SMK Negeri 1 Pematangsiantar asked Simalungun University in this case the Faculty of Economics to carry out a competency test for students sitting in class XII. Competency Test as one of the graduation requirements for students. The Skills Competency Test for students aims to a) measure the competency attainment of vocational students b) facilitate students to obtain competency test certificates c) optimize the implementation of competency certification for vocational students according to the Indonesian National Framework d) facilitate vocational schools in collaboration with the business/industry world as needed business and industry. The Skills Competency Test is held for 4 days, from April 5, 2021 to April 8,2021 . This competency test is not only carried out by the university world (higher education) but also involves the business world, namely during the interview exam. Based on the results obtained during the implementation, the Service Team from the Faculty of Economics, Simalungun University, the team from the business world and the team from SMK Negeri 1 Pematangsiantar stated that all participants had passed. Evaluation of the process of implementing the activities is carried out by giving questionnaires to students participating in the competency test. And the results obtained $25 \%$ gave very good answers, $60 \%$ gave good answers and $15 \%$ gave sufficient answers. So that in the future the implementation of the competency exam will be improved as suggested by students so that when the accounting practice exam each student uses a computer
\end{abstract}

Keywords: competence test; SMK; student; accountancy

PENDAHULUAN
Tujuan dari kegiatan pengabdian ini
adalah untuk mengukur pencapaian
pengetahuan dan ketrampilan siswa/siswi
jurusan akuntansi kelas XII SMK Negeri 1 Kota
Pematangsiantar dan memfasilitasi siswa untuk mendapatkan sertifikat keahliannya sebagai salah satu syarat kelulusan dengan melibatkan dunia pendidikan Perguruan Tinggi dan dunia usaha. UKK dilaksanakan oleh satuan pendidikan dalam bentuk ujian praktik yang menguji aspek pengetahuan, keterampilan, dan 
sikap. (Sudradjat \& Amyar, 2020) Sebagaimana Undang - undang nomor 20 tahun 2003 tentang Sistim Pendidikan Nasional menyebutkan bahwa pendidikan kejuruan merupakan pendidikan menengah yang mempersiapkan peserta didik untuk bekerja dalam bidang tertentu. Peraturan Menteri Pendidikan dan Kebudayaan Nomor 34 tahun 2018 tentang Standar Nasional Pendidikan SMK menyebutkan tujuan penilaian hasil belajar adalah untuk mengetahui tingkat capaian hasil belajar siswa, pertubuhan dan perkembangan peserta didi, mendiagnosis kesulitan belajar peserta didik, mengetahui efektivitas proses pembelajaran dan mengetahui capaian kurikulum. Uji Kompetensi Keahlian (UKK) adalah bagian dari intervensi Pemerintah dalam menjamin mutu pendidikan pada satuan pendidikan Sekolah Menengah Kejuruan. (Ahmad Yani, Yano Hurung Anoi, \& Wildan Hamdani, 2020) Uji Kompetensi Keahlian (UKK) merupakan proses penilaian melalui pengumpulan bukti yang relevan apakah seseorang kompeten atau belum kompeten pada suatu klasifikasi tertentu. (Sudradjat \& Djanegara, 2020) Atas dasar ini lah SMK Negeri 1 Pematangsiantar, mengundang Tim Pengabdi dari Fakultas Ekonomi Universitas Simalungun dan Tim dunia usaha untuk melaksanakan kegiatan Uji Kompetensi Keahlian di bidang Akuntansi pada tanggal 5 s/d 8 April 2021. SMK Negeri 1 Pematangsiantar melaksanakan uji kompetensi keahliah akuntansi ini berkeinginan melihat seberapa besar kompetensi yang dimiliki oleh siswa/siswi mereka di bidang akuntansi, setelah para siswa siswi tersebut telah menyelesaikan masa studi/masa pembelajaran selama 6 (enam) semester di bangku kelas.

\section{METODE}

Pelaksanaan kegiatan pengabdian ini dilaksanakan secara tatap muka dengan tetap mentaati protokol kesehatan. Kegiatan pengabdian ini dilaksanakan tanggal 5, 6, 7 dan 8 April 2021. Metode kegiatan pelaksanaan pengabdian adalah dalam bentuk ujian tertulis dan ujian wawancara. Sebelum kegiatan uji kompetensi dilaksanakan, terlebih dahulu disiapkan bahan-bahan ujian yaitu yang pertama ujian tertulis dalam bentuk pilihan ganda dan yang kedua adalah ujian tertulis praktek penyusunan laporan keuangan. Pada saat ujian tertulis Tim pengabdi berperan sebagai pengawas untuk menjamin bahwa siswa/siswi mengerjakan soal secara mandiri, tidak kerjasama atau tidak mencontek. Kegiatan ujian tertulis dilaksanakan dengan memperhatikan protokol kesehatan dengan membuat aturan satu siswa satu meja, sehingga konsep jaga jarak tetap dipenuhi dan satu ruangan maksimum 24 orang atau setengah dari daya tampung normal. Sedangkan ujian wawancara dengan cara satu pewawancara dan satu siswa/siswi yang diwawancarai satu persatu. Pelaksanaan kegiatan ujian kompetensi digambarkan dalam alur kegiatan seperti pada gambar 1 berikut :

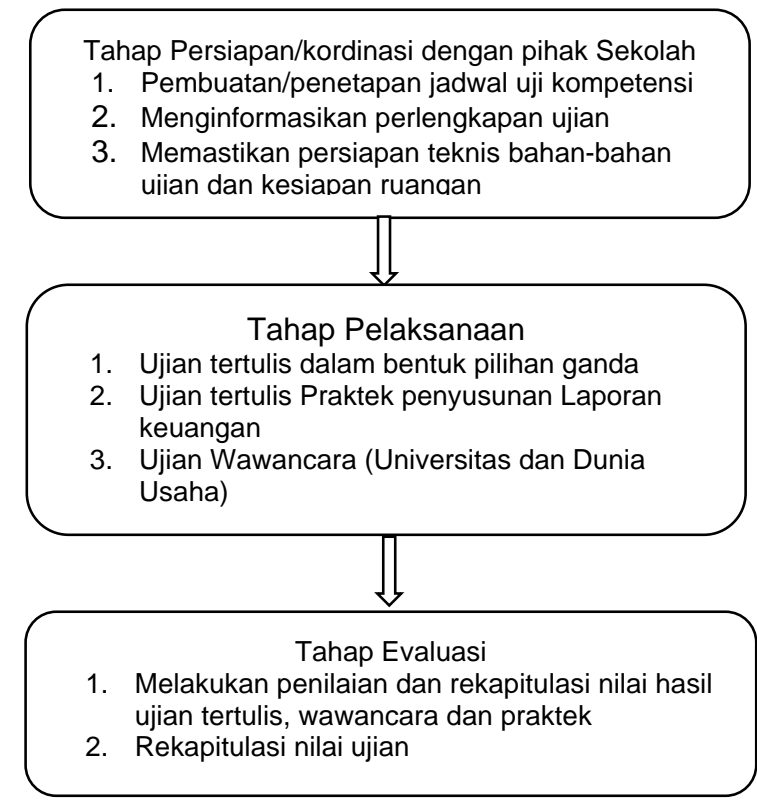

Gambar 1. Alur kegiatan

Kegiatan pengabdian ini terdiri dari tiga tahapan yaitu pertama tahap persiapan, kedua tahap pelaksanaan dan ketiga tahap evaluasi

\section{HASIL DAN PEMBAHASAN}

Tahap persiapan, dilaksanakan pada tanggal 5 April 2021. Tim pengabdi melakukan kordinasi dengan pihak Sekolah Menengah Kejuruan Negeri (SMKN) 1 Pematangsiantar, untuk memastikan agar kegiatan ujian kompetensi yang akan dilaksanakan dapat terlaksana dengan baik. Pemeriksaan terhadap persiapan ruangan kelas seperti ketersediaan meja kursi dan pengaturan jarak untuk mematuhi protokol kesehatan di masa pendemi covid-19 dan memastikan ketersedian bahan bahan ujian serta menginformasikan kepada siswa/siswi perihal peralatan ujian yang harus mereka persiapkan. Para siswa agar membawa peralatan ujian seperti pulpen, pensil, penggaris, penghapus atau tip ex dan alat hitung atau kalkulator.

Tahap kedua yaitu pelaksanaan ujian tertulis pada tanggal 6 April 2021. Ujian tertulis dibagi dalam dua bentuk yang pertama adalah ujian tertulis pilihan berganda dan yang kedua adalah ujian tertulis praktek yaitu menyusun laporan keuangan berdasarkan data yang 
transaksi keuangan yang sudah disiapkan oleh Tim Pengabdi dari Fakultas . Ujian pilihan berganda sebanyak 50 soal dengan batas waktu selama 60 menit yang berisikan istilah istilah dalam akuntansi dan laporan keuangan.

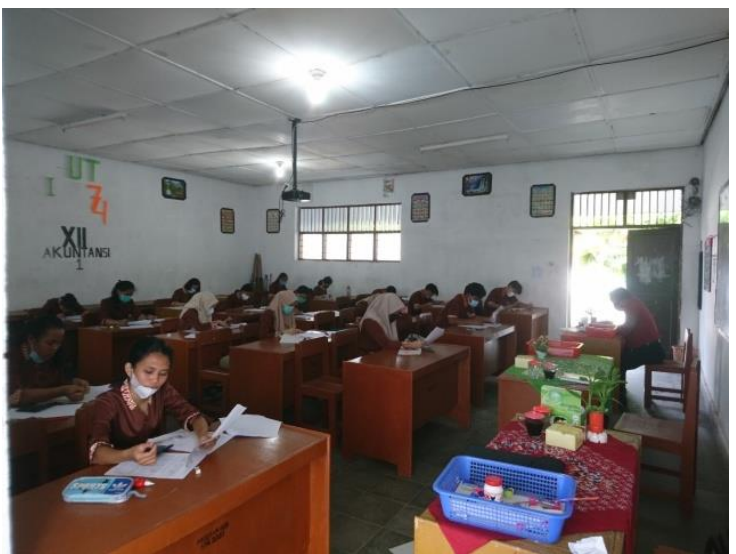

Gambar 2. Ujian tertulis pilihan berganda

Ujian yang kedua adalah ujian praktek akuntansi. Pada ujian praktek ini, Tim pengabdi meyiapkan sebuah data laporan posisi keuangan dan data transaksi keuangan harian yang terjadi dalam satu bulan sebuah perusahaan dagang.

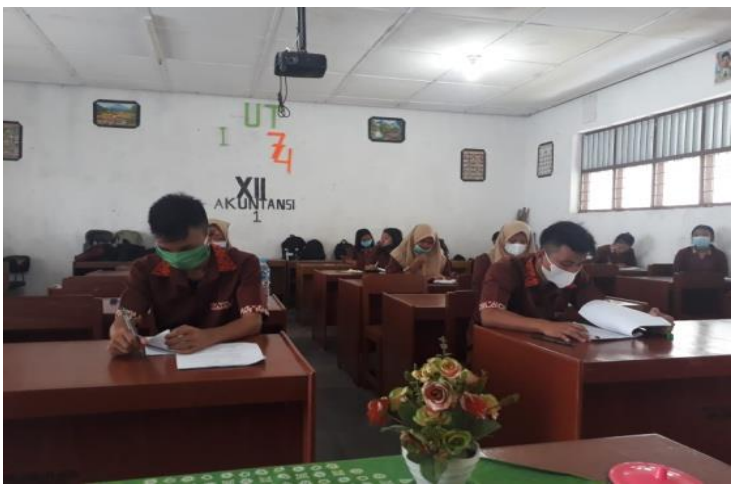

Gambar 3. Ujian tertulis praktek penyusunan Laporan Keuangan

Dalam tahap ujian tertulis praktek penyusunan laporan keuangan, diminta kepada siswa siswi untuk menyusun sebuah laporan keuangan., yang terdiri dari Laporan Posisi Keuangan, Laporan Laba Rugi, Laporan Arus Kas dan Laporan Perubahan Ekuitas. Siswasiswa harus menunjukkan proses akuntansi sehingga terlahir sebuah laporan keuangan dengan benar.

Tim pengabdi menyiapkan sebuah soal tertulis praktek penyusunan laporan keuangan : Ibu Melati mendirikan sebuah perusahaan salon kecantikan. Ibu Melati tidak mempunyai ketrampilan yang cukup untuk menyusun laporan keuangan, sementara di sisi lain, beliau ingin mengetahui apakah usaha yang dia dirikan dapat memperolah keuntungan dan layak untuk diteruskan. Sehingga dia membutuhkan seorang tenaga akuntansi yang dapat membantu. Anda seorang tenaga akunting dan lbu Melati meminta anda untuk menyusun laporan keuangan perusahaan tersebut

Adapun data transaksi yang terjadi di bulan Desember 2006 sejak beliau mendirikan usaha hingga tanggal 31 Desember 2006 adalah sebagai berikut.

1. Tanggal 2 Desember 2006 Ny. Melati mendirikan salon kecantikan yang diberi nama "Beauty Salon". Untuk modal pertama, disetorkan uang $\mathrm{Rp} 6.000 .000$ secara tunai ke "salon Gadis". (Bukti Kuitansi No. K.001)

2. Tanggal 2 Desember 2006 membayar sewa ruangan untuk bulan desember 2006 sebesar Rp 80.000 (No. K.002)

3. Tanggal 4 Desember 2006 membeli secara kredit peralatan salon dengan harga $\mathrm{Rp}$ 2.400 .000 (No. K.003)

4. Tanggal 5 Desember 2006 dibeli clensing cream, hair dye-lotion, dan perlengkapan lainnya seharga $\mathrm{Rp} 500.000$,- secara kredit seharga Rp 400.000 dan tunai Rp 100.000,(No. K004)

5. Tanggal 6 Desember 2006 dibayar beban pemasangan iklan mini di harian Metro Siantar sebesar Rp 150.000 (No. K005)

6. Tanggal 15 Desember 2006 dibayar gaji dan upah karyawan untuk tanggal 1-15 desember 2006 sebesar Rp 250.000. (No. K006)

7. Tanggal 15 Desember 2006 diterima uang kas sebesar $\mathrm{Rp} 780.000$ dari penjualan tunai selama setangah bulan pertama kegiatannya. (No. K007)

8. Pada tanggal 28 Desember 2006, permohonan Ny. Melati untuk mendapatkan kredit investasi kecil guna pembelian salon yang baru dari BNI 46 sebesar Rp 6.000.000 telah disetujui. (No .K008)

9. Tanggal 29 Desember 2006, dibeli peralatan salon dengan tunai sebesar $\mathrm{Rp} 4.800 .000$ (No.K009)

10.Tanggal 29 Desember 2006, dibayar gaji dan upah untuk tanggal 16-29 Desember 2006 sebesar Rp 250.000 (No.K010)

11.Tanggal 31 Desember 2006, diterima uang kas sebesar $\mathrm{Rp} 1.600 .000$ dari penjualan tunai selama setengah bulan terakkhir (No. K011)

12.Tanggal 31 Desember 2006, Ny. Melati mengambil uang sebesar $\mathrm{Rp} 500.000$ untuk keperluan pribadi. (No.K012)

Diminta kepada siswa/siswi untuk menyusun laporan keuangan sesuai dengan standar akuntansi yang berlaku dengan menunjukkan proses akuntansi, sebagai berikut 
a. Pencatatan penjurnalan

b. Posting dari jurnal ke buku besar

c. Membuat neraca saldo (trial balance) sebelum penyesuaian

d. Membuat jurnal penyesuaian untuk menyesuaikan akun akrual dan akun penangguhan

e. Membuat Neraca saldo yang disesuaikan

f. Membuat Laporan Keuangan :

1) Laporan Posisi Keuangan

2) Laporan Laba rugi

3) Laporan Arus Kas

4) Laporan Perubahan Modal (ekuitas)

f. Membuat jurnal penutup

g. Membuat secara saldo setelah penutupan

h. Membuat jurnal pembalik

Ujian tertulis praktek penyusunan laporan keuangan diberi waktu selama 150 menit $(2,5$ jam).

Pada hari ketiga yaitu tanggal 7 april 2021 dilakukan ujian wawancara. Ujian wawancara melibatkan dunia usaha. Tim pengabdi dan tim dari dunia usaha melakukan wawancara kepada siswa siswi untuk mengetahui seberapa jauh kedalam pengetahuan mereka perihal akuntansi dan manfaat dari laporan keuangan.

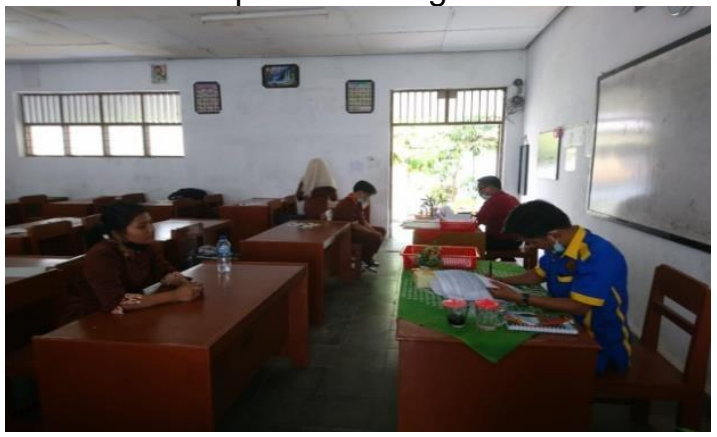

Gambar 4. Ujian wawancara

Metode pelaksanaan ujian wawancara dilakukan dengan cara memanggil satu - satu siswa/siswi.Tim pengabdi bebas menyampaikan pertanyaan seputar akuntansi dan laporan keuangan. Tim pengabdi melakukan eksplor untuk mengetahui kedalaman pengetahuan mereka tentang akuntansi dan laporan keuangan. Waktu wawancara untuk setiap peserta kisaran waktu 20 - 30 menit. Poin - poin wawancara yang disampaikan kepada siswa-siswi adalah sebagai berikut :

a. Proses akuntansi

b. Prinsip - prinsip dalam penyusunan laporan keuangan

c. Manfaat Laporan Keuangan

d. Kemampuan menganalisa laporan keuangan sehingga mampu memberikan saran/masukan/pendapat kepada pimpinan perusahaan dalam rangka profit dan sustainable
2021, Pada hari ke -4 yaitu tanggal 8 April angket/kuesioner yang berisikan mengenai proses uji kompetensi yang dilaksanakan. Hal ini dilakukan untuk menilai apakah model uji kompetensi yang dilaksanakan dapat bermanfaat dan melihat apakah model uji kompetensi ini perlu perbaikan dan peningkatan. Dan pada hari ke-4 Tim pengabdi dan Tim dari Sekolah SMK Negeri 1 Pematangsiantar, melakukan rapat dan membuat penilaian, atas hasil uji kompetensi yang dilaksanakan kepada siswa.

Berdasarkan hasil evaluasi terhadap uji kompetensi, seluruh siswa-siswa dinyatakan lulus. Dan hasil evaluasi atas kegiatan uji kompetensi, siswa siswa memberikan jawaban sangat baik $25 \%$, baik $60 \%$ dan cukup $15 \%$. Sehingga perlau peningkatan model ujian, Saran dari peserta yang memberikan penilaian cukup adalah agar ke depan pihak sekolah menyiapkan computer untuk memfasilitas ujian praktek penyusunan laporan keuangan, sehingga mempermudah kerja dalam hal waktu dan keakuratan perhitungan angkat

\section{SIMPULAN}

Kegiatan pengabdian kepada masyarakat yang dilaksanakan Tim Pengabdi dari Fakultas Ekonomi Universitas Simalungun berupa pelaksanaan uji kompetensi keahlian di bidang akuntansi pada SMK Negeri 1 Pematangsiantar berjalan dengan baik. Seluruh siswa/siswi mengikuti seluruh tahapan uji kompetensi tersebut, yaitu ujian tertulis bentuk pilihan ganda, uji tertulis bentuk praktek penyusunan laporan keuangan dan uji wawancara. Pada akhir kegiatan diberikan angket kepada peserta uji kompetensi untuk mengevaluasi kegiatan pengabdian tersebut dan meminta saran masukan dari siswa/siswi.

\section{SARAN}

Peserta uji kompetensi memberikan saran agar dalam pelaksaksanaan ujian tertulis praktek penyusunan laporan keuangan diberikan fasilitas komputer untuk memudahkan pekerjaan dan keakuratan angka dalam melakukan perhitungan.

\section{DAFTAR RUJUKAN}

Ahmad Yani, Yano Hurung Anoi, \& Wildan Hamdani. (2020). PELATIHAN PENINGKATAN KOMPETENSI PRA UJI KOMPETENSI KEJURUAN (UKK) JURUSAN TEKNIK OTOMOTIF KEPADA SISWA SMK RIGOMASI BONTANG. Jurnal Abdimas Bina Bangsa, 1(1), 128-136. https://doi.org/10.46306/jabb.v1i1.48 
Irwanti, Y. D., \& Sudira, P. (2014). Evaluasi uji kompetensi siswa keahlian multimedia di SMK se-Kota Yogyakarta. Jurnal Pendidikan Vokasi, 4(3). https://doi.org/10.21831/jpv.v4i3.2564

Kartowagiran, B. (2018). Optimalisasi Uji Tingkat Kompetensi di SMK untuk Meningkatkan Soft Skill Lulusan. Jurnal Dinamika Vokasional Teknik Mesin, 3(2), 101-109. https://doi.org/10.21831/dinamika.v3i2. 21406

Marhendi, T. (2021). Penerapan Uji Kompetensi Untuk Meningkatkan Kompetensi Lulusan SMK Muhammadiyah 1 Purwokerto. Jurnal Pengabdian Teknik Dan Sains (JPTS), 1(1). https://doi.org/10.30595/.v1i1.9372

Putri, F., Yoto, \& Sunarto, Y. (2017). Studi Pengelolaan Pelaksanaan Uji Kompetensi Keahlian di SMK PGRI 3 Malang. Jurnal Pendidikan Profesional, 6, No.2(Jurnal Pendidikan), 191-203

Rahmawati, L. (2019). Manajemen Pelatihan Kompetensi Guru Akuntansi untuk Meningkatan Kompetensi Profesional dalam Mempersiapkan Uji Kompetensi Siswa SMK. Prosiding Seminar Nasional Manajemen

Sudradjat, S., \& Amyar, F. (2020). PKM Uji Kompetensi Bidang Keahlian Akuntansi di SMK Pembangunan Kota Bogor. Jurnal Abdimas Dedikasi Kesatuan, 1(1), 37-42. https://doi.org/10.37641/jadkes.v1i1.32 1

Suranto, S., Muhyadi, M., \& Mardapi, D. (2014). PENGEMBANGAN INSTRUMEN EVALUASI UJI KOMPETENSI KEAHLIAN (UKK) ADMINISTRASI PERKANTORAN DI SMK. Jurnal Penelitian Dan Evaluasi Pendidikan, 18(1), 98-114. https://doi.org/10.21831/pep.v18i1.212 7

Sudradjat, S., \& Djanegara, M. S. (2020). PKM Uji Kompetensi Bidang Keahlian Akuntansi Di SMK Bina Sejahtera Kota Bogor. Jurnal Abdimas Dedikasi Kesatuan, 1(1), 21-28. https://doi.org/10.37641/jadkes.v1i1.31 9

Santiyadnya, N. (2011). IMPLEMENTASI UJI KOMPETENSI DAN PENGARUHNYA TERHADAP KUALITAS LULUSAN SMK NEGERI BIDANG TEKNOLOGI DI PROVINSI BALI. Jurnal Pendidikan Teknologi Dan Kejuruan, 8(1). https://doi.org/10.23887/jptk.v8i1.2889
Peraturan Menteri Pendidikan dan Kebudayaan Nomor 34 tahun 2018 tentang Standar Nasional Pendidikan SMK/MAK

Undang - Undang Sistem Pendidikan Nasional No 20 tahun 2003 tentang Sistem Pendidikan Nasional

Widayati, A., \& Isroah, I. (2014). EVALUASI PELAKSANAAN UJI KOMPETENSI PRODUKTIF SMK PROGRAM KEAHLIAN AKUNTANSI. Jurnal Pendidikan Akuntansi Indonesia, 5(1). https://doi.org/10.21831/jpai.v5i1.867 